\title{
Zoopery study on the treatment of intracranial aneurysms with a new blood flow guide device
}

\author{
Chunguang Chen ${ }^{1,2}$, Fei Liang ${ }^{1}$, Yupeng Zhang ${ }^{1}$, Chuhan Jiang ${ }^{1}$ \\ ${ }^{1}$ Department of Interventional Neuroradiology, Beijing Neurosurgical Institute and Beijing Tiantan Hospital, Capital Medical University, Beijing, \\ China; ${ }^{2}$ Department of Neurosurgery, Liaoyang central hospital, Liaoyang, China \\ Contributions: (I) Conception and design: C Chen, C Jiang; (II) Administrative support: F Liang, Y Zhang; (III) Provision of study materials or \\ patients: None; (IV) Collection and assembly of data: C Chen, F Liang; (V) Data analysis and interpretation: Y Zhang, C Jiang; (VI) Manuscript \\ writing: All authors; (VII) Final approval of manuscript: All authors. \\ Correspondence to: Chuhan Jiang. No. 119, South 4th Ring Road, Fengtai District, Beijing 100070, China. Email: jiangchuhan@163.com.
}

\begin{abstract}
Background: The purpose of this study was to evaluate the safety and effectiveness of arterial embolism device system produced by Taijie Weiye Technology Co., Ltd.

Methods: Twenty healthy adult New Zealand white rabbits weighting from 3 to $4 \mathrm{~kg}$ were taken. Ligation and Elastic induction were used to build the aneurysm model of right common carotid artery in rabbits. The angiography and the arterial embolization device were implanted four weeks after the animal models were established. This device has excellent manufacturing, good controllability, and smooth pushing process. Five rabbits were randomly selected for angiography test to observe the healing of aneurysms in the first month, the third month and the sixth month after operation. Three other animal models with successful implantation were examined by arteriography in the first month, the third month and the sixth month, and the effect of implantation device on intercostal artery was recorded and analyzed.
\end{abstract}

Results: In the process of making aneurysm models, sixteen animals were successfully implanted with one device, two animals were given overlapping devices, and only two animals died in the process. The success rate of arterial embolic device system in the treatment of aneurysm was more than $80 \%$. Among them, the two animals with 2 devices also achieved satisfactory therapeutic effect.

Conclusions: According to this study, we found that the arterial embolization device system manufactured by Beijing Tajie Weiye Science and Technology Co., Ltd. was excellent in the immediate postoperative aneurysm occlusion rate and the long-term outcomes.

Keywords! Intracranial aneurysms; arterial embolism device system; occlusion; stenosis

Submitted May 23, 2020. Accepted for publication Dec 09, 2020.

doi: 10.21037/apm-20-1160

View this article at: http://dx.doi.org/10.21037/apm-20-1160

\section{Introduction}

Intracranial aneurysm (IA) which is an abnormal dilatation on the wall of intracranial artery is the main cause of subarachnoid hemorrhage (1). Once ruptured, the mortality and disability rate are very high. As a great breakthrough in the endovascular treatment of intracranial aneurysms, the device that reflects the change of the treatment concept from plugging aneurysms to remodeling aneurysmal arteries is a new method for the treatment of complex aneurysms (2).
Blood flow guidance device [flow diverters (FDs)] has been used in recent years A new type of intracranial aneurysm hemodynamics Dense mesh support. Through high metal coverage and low mesh design, FD can reshape local blood flow and move the tumor-carrying artery into the aneurysm Impact blood flow is directed to the distal normal vessel to reduce local blood flow. The impact of the aneurysm improves the hemodynamics in the aneurysm, and causes tumor thrombosis and aneurysm occlusion. Meanwhile, a fine net silk is beneficial to the growth of the intima of 
the artery, thus realizing the release of the tumor-carrying artery. Reconstruction Different from other blood flow guide devices, the arterial blood flow guide system produced by Taijie Weiye Technology Co., Ltd. is made of highperformance medical nickel titanium alloy (Nitinol). And according to the mechanical properties, chemical properties, and biocompatibility of the stent, $30-40 \%$ of the metal coverage is provided at the site of the aneurysm. This paper will evaluate the safety and effectiveness of this arterial embolization system in the treatment of aneurysms by animal experiments. We present the following article in accordance with the ARRIVE reporting checklist (available at http:// dx.doi.org/10.21037/apm-20-1160).

\section{Methods}

\section{Rabbits aneurysm model of the right common carotid artery}

Twenty healthy adult New Zealand white rabbits $(3-4 \mathrm{~kg})$ with no limit between male and female were purchased from the animal experiment center of Capital Medical University. Experiments were performed under a project license (No. 2017PS263K) granted by institutional ethics committee of Beijing Neurosurgical Institute and Beijing Tiantan Hospital, in compliance with Capital Medical University institutional guidelines for the care and use of animals (No. 211002300056495).

Feeding environment: Constant temperature $\left(23 \pm 2{ }^{\circ} \mathrm{C}\right)$, constant humidity $(50 \% \pm 2 \%)$, sound insulation, electrostatic shielding, automatic light control for $12 \mathrm{~h} / 12 \mathrm{~h}$ light and dark cycle (lamp opening time is 7 hours, lamp turning off time is 19 hours), illumination intensity is 100 Lux. Animals can freely obtain food and water and have free movement. Each operation during the experiment does its best to reduce the suffering of the animals.

\section{The aneurysm model was established by ligating and elastase induction}

\section{Preoperative preparation}

All animals were fasted 12 hours before operation. After disinfection, the needle holder was used to hold the root of the aneurysm clip, so that the power of the aneurysm clip was just enough to block the blood flow without causing vascular damage.

\section{Anesthesia}

Venous passage was established by indwelling venous cannula needle from ear vein puncture in rabbits. $10 \%$ chloral hydrate solution was injected into the intravenous at the dose of $2 \mathrm{~mL} / \mathrm{kg}$, and was stopped while the time muscle strength weakened but corneal reflex still existed. The injection time must be more than 10 minutes.

\section{Surgical plan}

Rabbits with neck overextended were fixed with bandage, and placed supine. After disinfection, the rabbit's neck skin was cut with a blade along the median line, and the subcutaneous tissue was separated layer by layer until the trachea and the right common carotid artery were exposed. The right arteria carotid communis were free, and 2 threads were put under the RCCA which was separated along the lateral edge of the right chest sternocleidomastoid muscle. RCCA was temporarily blocked near the heart and the lateral wall of the artery was cut open at the distal end with the aneurysm clip. Then the 6F artery sheath was placed and fixed with a No. 1 thread, and RCCA was ligated distal with thread. The $6 \mathrm{~F}$ guide catheter was sent into the arterial sheath, the Hyperform $4 \mathrm{~mm} \times 7 \mathrm{~mm}$ balloon was first sent into the RCCA along the guide catheter, the blood pulsation disappeared after filling the balloon, and the balloon was slowly sent to the proximal end of the artery. When the blood flow in the internal carotid artery beat again, it proved that the balloon has entered the anonyma. Then enlarge the balloon and pull it back again. The balloon was successfully located at the opening of RCCA and the right internal carotid artery was closed when the pulsatile disappeared. The Echelon 10 microcatheter was sent to the proximal end of RCCA along the guide tube, and $75 \mathrm{U}$ elastase solution was injected into the closed cavity at the beginning of RCCA. The microcatheter was pulled out after 20 minutes' digestion. The Y valve was opened first, and then the balloon was deflated. So that the blood could flush the elastase into the $\mathrm{Y}$ valve, and block the proximal end of the artery again. Slowly pull out the arterial sheath, ligate the RCCA puncture orifice, infiltrate the operation area with gentamicin, and wipe the operation area with iodophor. Then the subcutaneous tissue and skin were sutured layer by layer. After that, the date and name of the experiment were recorded in the right ear of the rabbit. At last, the rabbits were sent back to the animal room (Figure 1). 

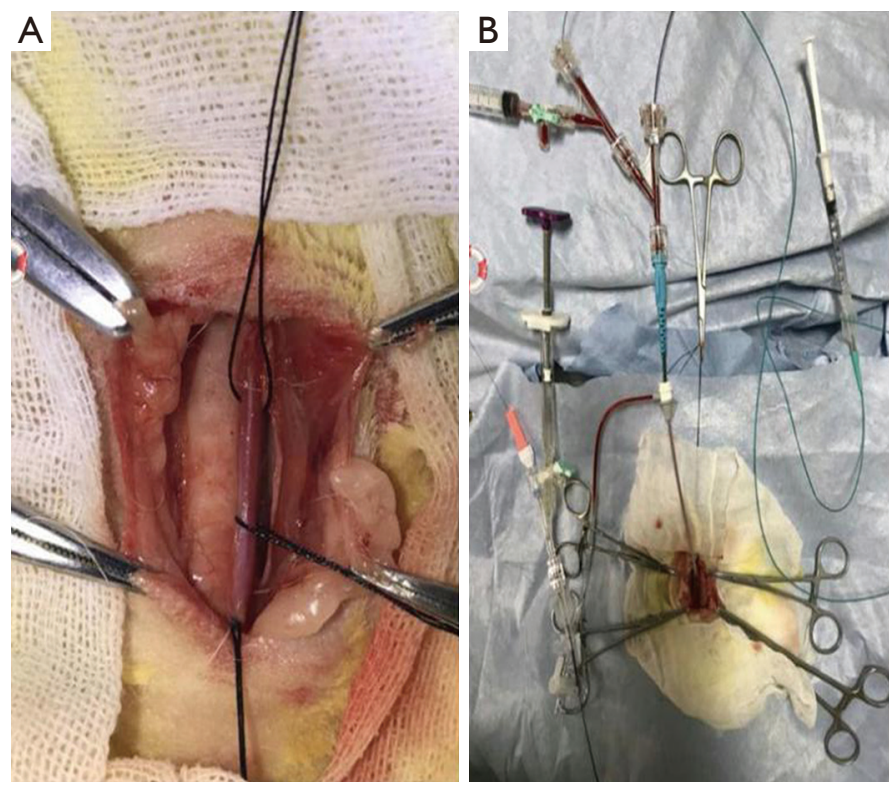

Figure 1 Establishment of rabbits' aneurysm model. (A) Experimental rabbit's neck exposure; (B) material for overall operation.

\section{Postoperative treatment}

After operation, the experimental rabbits were fed in different cages with the neck straightened and tilted to one side, so as to avoid asphyxia caused by the compression of the airway through the neck. The experimental rabbits were closely observed until they woke up completely. The vital signs of the animals and the bleeding or emphysema in the neck were closely observed. Penicillin with the dose of $80,0000 \mathrm{U} / \mathrm{d}$ was injected intramuscular for 3 days after operation.

\section{Follow-up monitoring}

All rabbits underwent digital subtraction angiography 4 weeks after operation, and the success rate of the aneurysm was examined. The short, long, neck and carrier diameter of aneurysms were measured and analyzed.

\section{Intravascular interventional therapy}

Angiography and arterial embolization were performed 4 weeks after the establishment of the arterial model.

\section{Preoperative preparation}

Aspirin $(10 \mathrm{mg} / \mathrm{kg})$ and clopidogrel $(10 \mathrm{mg} / \mathrm{kg})$ were given to animals two days before operation. And the animals were fasting on the day of operation. Venous passage was established by indwelling venous cannula needle from ear vein puncture in rabbits. $10 \%$ chloral hydrate solution was injected into the intravenous at the dose of $2 \mathrm{~mL} / \mathrm{kg}$, and was stopped while the time muscle strength weakened but corneal reflex still existed. The process of injection must be more than 10 minutes. Device implantation process: the rabbits were fixed on the self-made surgical board in supine position, fixed with bandage, and prepared skin disinfection. Then the skin was cut at the root of the right lower extremity along the most obvious pulsatile of the thigh artery, the subcutaneous layers of tissue was separated, and the right thigh artery was exposed. When the femoral artery was free, it was occluded at the proximal end of the patent ductus arteriosus by bulldog clamp and ligated with a silk thread at the distal end $3 \mathrm{~cm}$ from the aortic clamp. The clamping segment of femoral artery was pierced with a $4 \mathrm{~F}$ puncture needle. After bleeding, the artery clip was removed. Then the Loach guide wire and $4 \mathrm{~F}$ artery sheath were quickly sent into the femoral artery, and fixed with silk thread. The $4 \mathrm{~F}$ catheter was delivered to the aortic arch or brachiocephalic trunk via an arterial catheter in a perspective. One $\mathrm{mL}$ iodoverol was injected into the catheter for hand-hand subtraction in order to observe the vessel and the aneurysm. Then the guide wire was used to carry the microcatheter to the position of the aneurysm. The appropriate aneurysm embolism device was selected according to the diameter and the position of the artery. The blood flow guide device was used to cover the 

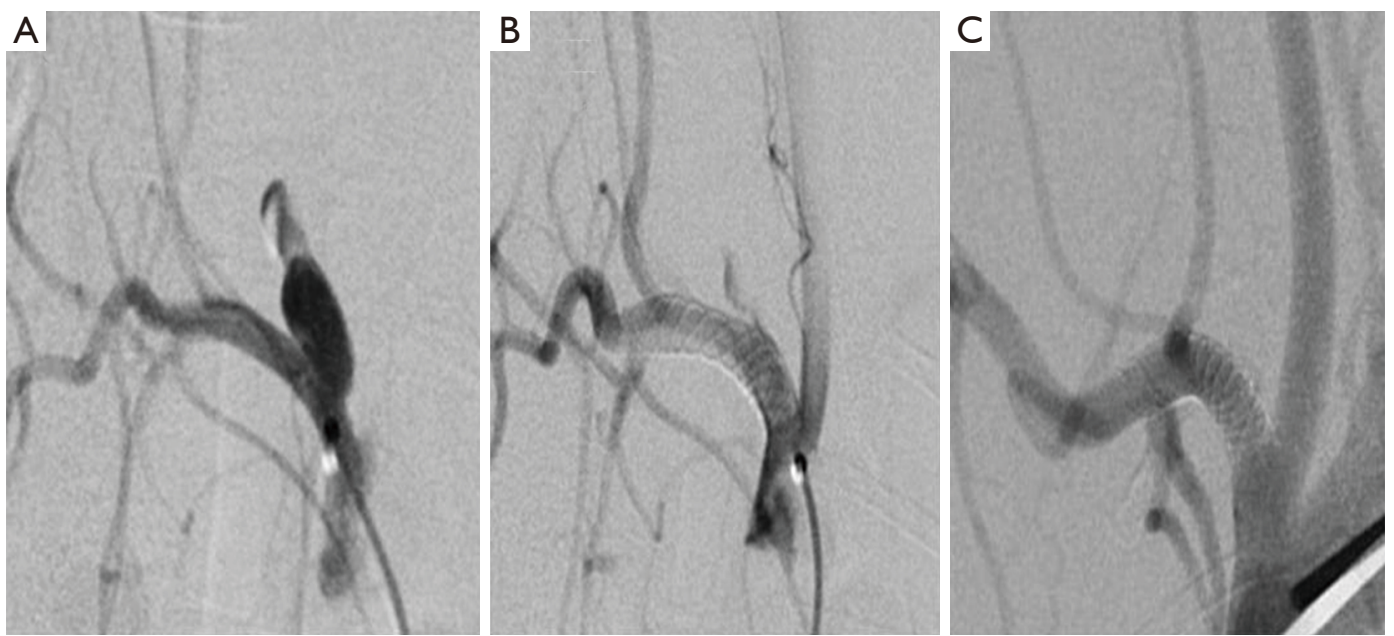

Figure 2 The first month group animal model aneurysm embolization display. (A) Preoperative angiography confirmed the formation of the aneurysm; (B) the blood in the aneurysm was immediately visible after the device was implanted; (C) 1 month after operation, the aneurysm disappeared completely, the tumor-carrying artery was unobstructed, the tumor-carrying artery was not narrow, and the vertebral artery was unobstructed and no occlusion was found. The experimental animals had no symptoms.

tumor neck, and then the guide catheter was withdrawn to the thoracic aortic. The intercostal artery was covered with an arterial embolism device. The development effect, release, recovery, and push effect of the arterial embolism device were observed during the operation. After that, the microcatheter and artery sheath were removed. The right thigh artery was ligated, the wound was sutured, and the rabbits were sent back to the animal room.

\section{Post-operative treatment}

The animals were closely observed until they completely waked. Then the penicillin with a dose of $80,000 \mathrm{U} / \mathrm{d}$ was injected intramuscular for 3 days. The anti-platelet drug aspirin $(10 \mathrm{mg} / \mathrm{kg} /$ day $)$ and chlordecay $(10 \mathrm{mg} / \mathrm{kg} /$ day $)$ were continued after the procedure for 30 days.

\section{Follow-up monitoring}

Five rabbits were randomly selected for angiography at the first month, third month and sixth months after operation, and the healing of aneurysm was observed.

\section{Statistical analysis}

SPSS 22.0 was used in this study. Statistical analysis a large proportion of data were presented as primary numbers, only one group of data was presented as mean \pm SEM. Statistical analysis was performed using descriptive analysis.

\section{Results}

The success rate of aneurysm manufacture and the data
analysis of the arterial contrast measurement analysis of the arterial contrast measurement

Two rabbits (No. 3 and No. 14) died during the postoperative feeding process. The remaining 18 rabbits were confirmed to be an aneurysm model by transarterial examination after 4 weeks of feeding (Figure 2). The success rate of aneurysm model was calculated. The short diameter, long diameter, aneurysm neck and diameter of tumor-carrying aneurysm were measured, and the data were recorded in Tables 1,2. The data of the aneurysm was analyzed and recorded in Table 3.

\section{Analysis of aneurysm bealing, tumor-bearing artery, and branch vessel changes}

Arterial embolic device was successfully implanted in 18 animal models, of which 16 animals were successfully implanted with one device, and the other 2 animals (No. 5 and No. 11) were given overlapping placement. Two overlapping animal models were selected and 13 animals were randomly selected from other 16 animals. A total of 15 animal models were randomly divided into three groups with 5 animals in each group. The data of the aneurysm healing and the changes in the tumor-carrying arteries were recorded and analyzed in the first month, the third month, 
Table 1 Success rate of aneurysm manufacture

\begin{tabular}{lccc}
\hline Number of animals & Number of aneurysm making & Number of successful aneurysms & Success rate of aneurysm making \\
\hline 20 & 20 & 18 & $90 \%$ \\
\hline
\end{tabular}

Table 2 Arteriography measurement data 4 weeks after elastase-induced aneurysm of the rabbit $/ \mathrm{mm}$

\begin{tabular}{lcccc}
\hline Animal No. & Short-diameter & Long-diameter & Neck width & Artery diameter \\
\hline 1 & 2.03 & 3.21 & 2.89 & 2.72 \\
2 & 3.12 & 5.05 & 3.23 & 3.11 \\
4 & 2.56 & 4.82 & 3.05 & 2.89 \\
5 & 3.80 & 5.56 & 3.53 & 3.35 \\
6 & 2.12 & 3.32 & 2.08 & 3.13 \\
7 & 4.58 & 7.35 & 3.45 & 3.30 \\
8 & 3.34 & 5.36 & 3.50 & 3.21 \\
9 & 3.80 & 7.62 & 3.60 & 3.40 \\
10 & 4.01 & 8.24 & 3.98 & 3.35 \\
11 & 4.35 & 6.78 & 3.58 & 3.26 \\
12 & 2.98 & 5.03 & 3.12 & 2.97 \\
13 & 3.76 & 6.61 & 3.15 & 3.03 \\
15 & 2.10 & 5.78 & 2.45 & 2.79 \\
16 & 5.23 & 9.34 & 5.65 & 3.32 \\
17 & 3.08 & 7.51 & 4.23 & 3.14 \\
18 & 3.45 & 6.85 & 3.12 & 2.89 \\
19 & 4.05 & 7.36 & 3.89 & 3.23 \\
20 & 3.01 & 7.53 & 3.40 & 3.10 \\
\hline
\end{tabular}

Table 3 Analysis of arteriography data 4 weeks after elastase induced-aneurysm in rabbits $/ \mathrm{mm}$

\begin{tabular}{lccc}
\hline Short-diameter & Long-diameter & Neck width & Artery diameter \\
\hline $3.41 \pm 0.88$ & $6.30 \pm 1.65$ & $3.49 \pm 0.80$ & $3.12 \pm 0.20$ \\
\hline
\end{tabular}

and the sixth month by an arteriography. selecting the remaining three animal models as group B, and randomly dividing into three groups, each group contained 1 animal. The effect of the implanted device on the intercostal artery was recorded and analyzed by the arteriography in the first month, the third month, and the sixth month (Figures 3,4). The grouping is shown in Table 4.

\section{Analysis of postoperative angiography}

The success rate of arterial embolic device system in the treatment of aneurysm was more than $80 \%$ no matter in the first month, the third month or the sixth month. Among them, the two animals with 2 devices also achieved satisfactory therapeutic effect, and the aneurysm was completely occlusive. The results of 3 animal models in 

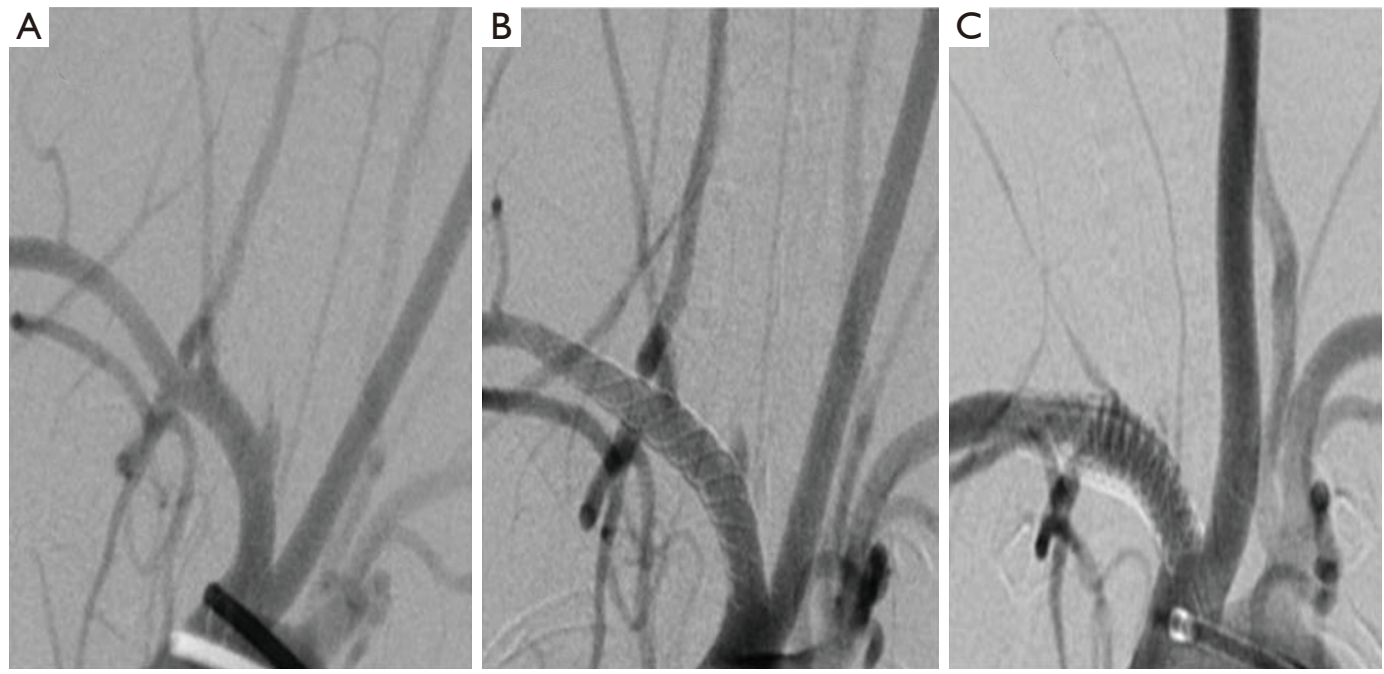

Figure 3 The third month group animal model aneurysm embolization display. (A) The formation of aneurysm was confirmed by preoperative angiography; (B) immediately after the implantation of the device, blood retention in the aneurysm could be seen, and the blood flow in the right vertebral artery was smooth; (C) 3 months after the operation, the aneurysm disappeared completely, the tumorcarrying artery was unobstructed, and the right vertebral artery was occluded. The experimental animals had no symptoms.
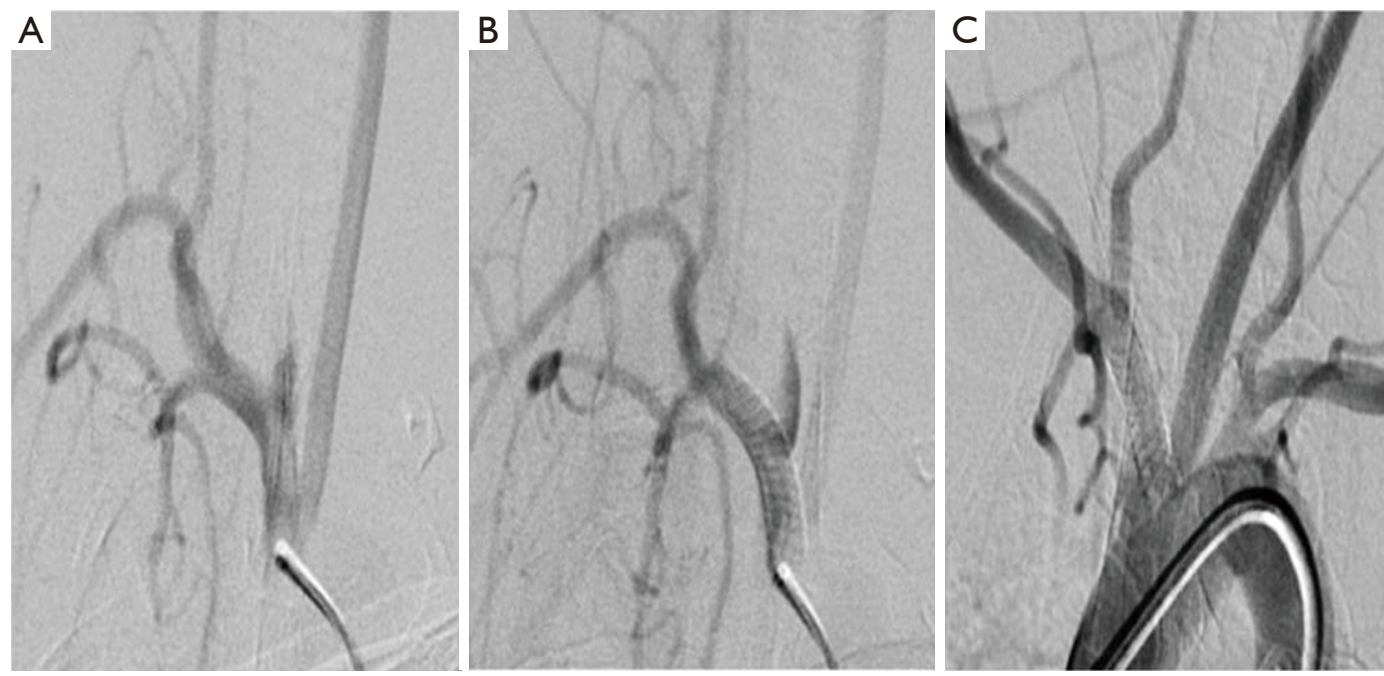

Figure 4 The sixth month group animal model aneurysm embolization display. (A) The formation of aneurysm was confirmed by preoperative angiography; (B) immediately after the implantation of the device, blood retention in the aneurysm could be seen; (C) 6 months after the operation, reexamination showed that the aneurysm disappeared completely, the distal blood vessels were unobstructed, and no stenosis was found in the tumor-carrying artery. The experimental animals had no symptoms.

the first month group, the third month group and the sixth month group showed that the intercostal artery was unobstructed and no occlusion and stenosis were found (Figure 5, Table 5).

\section{Discussion}

In this study, we found that the success rate of arterial embolic device system in the treatment of aneurysm was more than $80 \%$, and the implantation device did not cause 
Table 4 Grouping of animal models

\begin{tabular}{|c|c|c|c|c|c|c|}
\hline Animal grouping & \multicolumn{3}{|c|}{ Group A } & \multicolumn{3}{|c|}{ Group B } \\
\hline Animal number & $4,7,11,12,16$ & $1,5,8,15,20$ & $2,9,13,18,19$ & 10 & 6 & 17 \\
\hline
\end{tabular}
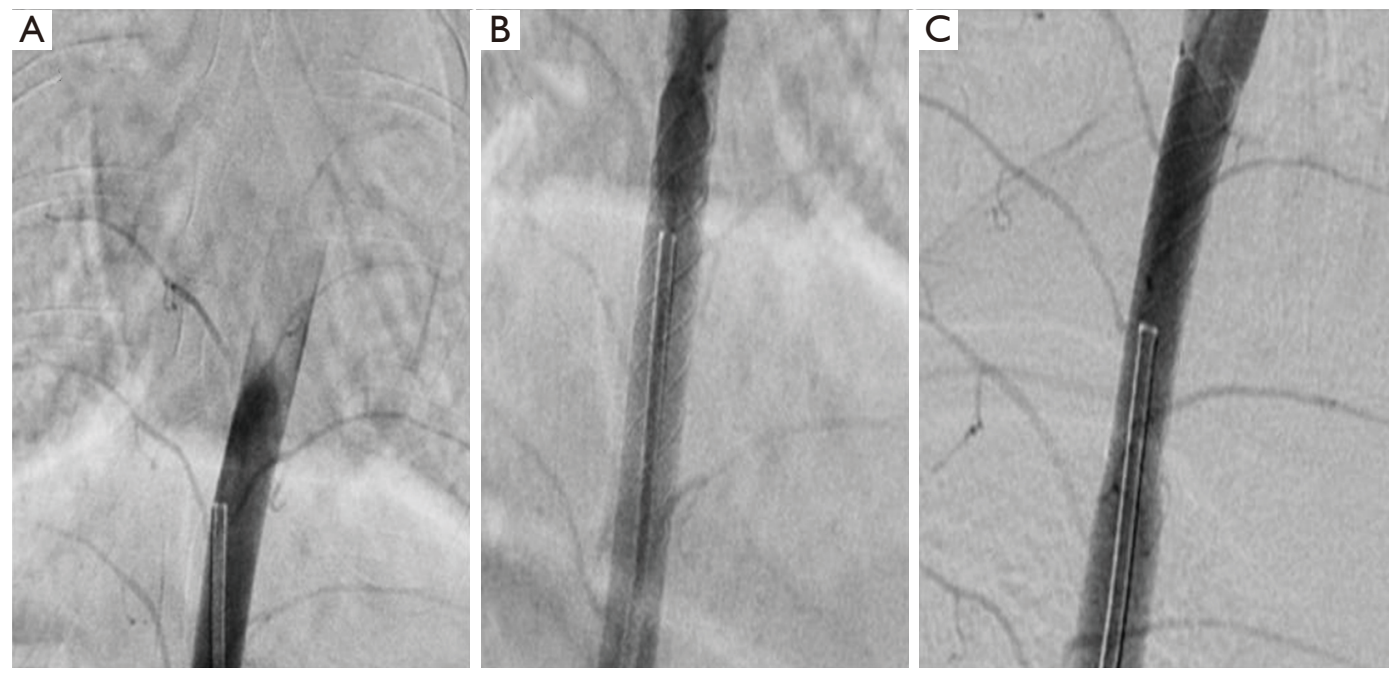

Figure 5 Display of perforating artery in covered animal model. (A) Preoperative angiography confirmed intercostal artery patency; (B) the intercostal artery was unobstructed by angiography immediately after device implantation; (C) the intercostal artery was still unobstructed 3 months after operation. The experimental animals had no symptoms.

Table 5 Angiographic record after treatment of aneurysm

\begin{tabular}{lcccc}
\hline Effectltime & $\begin{array}{c}\text { Immediately after surgery } \\
(\mathrm{n}=18)\end{array}$ & $\begin{array}{c}\text { The first month group } \\
(\mathrm{n}=6)\end{array}$ & $\begin{array}{c}\text { The third month group } \\
(\mathrm{n}=6)\end{array}$ & $\begin{array}{c}\text { The sixth month group } \\
(\mathrm{n}=6)\end{array}$ \\
\hline Partial occlusion (<90\%) & 13 & 0 & 0 & 0 \\
Near total occlusion (90-99\%) & 5 & 1 & 6 & 1 \\
Entirely occlusion shut (100\%) & 0 & 5 & $100 \%$ & 5 \\
Success rate & 0 & $83.3 \%$ & $83.3 \%$ \\
\hline
\end{tabular}

The criterion for successful treatment of aneurysm is $100 \%$ complete occlusion of aneurysm and no stenosis of tumor-bearing artery $>50 \%$.

any occlusion and stenosis to the covered branches. One animal of the sixth month group in the group A (animal number 9) showed a significant blood retention in the aneurysm after the device implantation. But the aneurysm was still developed at 6-month review. After analyzing we thought the reason was that the device was a little smaller than the aneurysm neck as the aneurysm was a shuttle- type expansion. Study from this case we learned that the diameter of the device should be greater than the diameter of the aneurysm and the length of the device should be at least $6 \mathrm{~mm}$ longer than the length of the aneurysm. According to the operation, imaging, and histopathological examination in the above experiment, we found that the success rate of the aneurysm model of the rabbit was high 
with the balloon-combined elastase method. The method can be used as the choice of the animal experiment of the interventional material.

At present, the main methods of establishing intracranial aneurysm models are etiological induction $(3,4)$, arteriovenous transplantation $(5,6)$ and intravascular intervention $(7,8)$ both at home and abroad. Endovascular intervention is a widely used animal model of intracranial aneurysm in recent years. This method needs to be completed under DSA or fluorescence microscope, so the cost is high. But the success rate of this method is lower than our method and the trauma is also greater. Although the success rate of previous blood flow guided devices is high, it is not uncommon for stents to fail to be fully opened in the successful delivery and release of these stents. In the early multi-centre study of silk FD by Byme et al., $29 \%(20 / 70)$ of technology-related complications occurred, including 12 cases (17\%) of malopening stents, resulting in 7 cases of parent artery occlusion (9). In this experiment, the modified method of intravascular intervention combined with the induction of pancreatic elastase was made after detailed study, analysis, and comparison of the above models, and finally according to the method of model making in David F. Kallmes series (10). This method only needs to expose the distal end of the carotid artery, and judge the origin of the internal carotid artery by using the different diameter of anonyma and the internal carotid artery without exposing the origin of the carotid artery, cutting open the sternum and separating the subclavian vein. It reduced the difficulty of the operation and greatly downsided the experimental mortality. The elastic enzyme solubility, the incubation time, the artery ligation point and the confirmed aneurysm contrast time were carried out in strict accordance with the David F. Kallmes experiment. Finally, a very ideal experimental model was obtained, and the pathology was confirmed to be similar to that of the human aneurysm. In the process of this experiment, the balloon catheter was firstly sent into the anonyma to temporarily block the anterior part of the vertebral artery. Then the balloon was deflated after hatching with digestive enzyme, and the digestive enzyme was washed out into the internal carotid artery to drain out of vitro. Finally, fusiform aneurysm was successfully made. And further experiments were suggested to establish other different forms of aneurysm such as lobulated aneurysm in order to provide a variety of patterns.

In the course of the experiment, the main function indexes (push performance, release performance, recyclability and visibility) of the arterial embolism device system produced by Beijing Taijie Weiye Technology Co., Ltd. performed very well. The product has excellent manufacturing, good controllability, smooth pushing process, and clear indication of the Mark point at the near end under the DSA. The only insufficient is that the development itself is a little ambiguous. The device can be recovered before the near-end marker point. It is said that the release of no more than $90 \%$ can be re-adjusted and released, which is particularly important in the case where the device release position is not satisfactory. The operation of the arterial embolization device system requires the surgeon to have a certain experience of aneurysm embolization, particularly in the use of the device.

\section{Conclusions}

To sum up, the arterial embolization device system manufactured by Beijing Tajie Weiye Science and Technology Co., Ltd. is excellent in the immediate postoperative aneurysm occlusion rate and the long-term outcomes.

\section{Acknowledgments}

Funding: None.

\section{Footnote}

Reporting Checklist: The authors have completed the ARRIVE reporting checklist. Available at http://dx.doi. org/10.21037/apm-20-1160

Data Sharing Statement: Available at http://dx.doi. org/10.21037/apm-20-1160

Conflicts of Interest: All authors have completed the ICMJE uniform disclosure form (available at http://dx.doi. org/10.21037/apm-20-1160). The authors have no other conflicts of interest to declare.

Ethical Statement: The authors are accountable for all aspects of the work in ensuring that questions related to the accuracy or integrity of any part of the work are appropriately investigated and resolved. Experiments were performed under a project license (No. 2017PS263K) granted by institutional ethics committee of Beijing Neurosurgical Institute and Beijing Tiantan Hospital, in compliance with Capital Medical University institutional 
guidelines for the care and use of animals (No. 211002300056495).

Open Access Statement: This is an Open Access article distributed in accordance with the Creative Commons Attribution-NonCommercial-NoDerivs 4.0 International License (CC BY-NC-ND 4.0), which permits the noncommercial replication and distribution of the article with the strict proviso that no changes or edits are made and the original work is properly cited (including links to both the formal publication through the relevant DOI and the license). See: https://creativecommons.org/licenses/by-nc-nd/4.0/.

\section{References}

1. van Donkelaar CE, Bakker NA, Veeger NJ, et al. Predictive Factors for Rebleeding After Aneurysmal Subarachnoid Hemorrhage: Rebleeding Aneurysmal Subarachnoid Hemorrhage Study. Stroke 2015;46:2100-6.

2. Ji T, Guo Y, Huang X, et al. Current status of the treatment of blood blister-like aneurysms of the supraclinoid internal carotid artery: A review. Int J Med Sci 2017;14:390-402.

3. Eldawoody H, Shimizu H, Kimura N, et al. Simplified experimental cerebral aneurysm model in rats: comprehensive evaluation of induced aneurysms and arterial changes in the circle of Willis. Brain Res

Cite this article as: Chen C, Liang F, Zhang Y, Jiang C. Zoopery study on the treatment of intracranial aneurysms with a new blood flow guide device. Ann Palliat Med 2021;10(3):28152823. doi: 10.21037/apm-20-1160
2009;1300:159-68.

4. Cai J, He C, Yuan F, et al. A novel haemodynamic cerebral aneurysm model of rats with normal blood pressure. J Clin Neurosci 2012;19:135-8.

5. Ding Y, Dai D, Kadirvel R, et al. Creation of large elastaseinduced aneurysms: presurgical arterial remodeling using arteriovenous fistulas. AJNR Am J Neuroradiol 2010;31:1935-7.

6. Kolega J, Gao L, Mandelbaum M, et al. Cellular and molecular responses of the basilar terminus to hemodynamics during intracranial aneurysm initiation in a rabbit model. J Vasc Res 2011;48:429-42.

7. Cloft HJ, Altes TA, Marx WF, et al. Endovascular creation of an in vivo bifurcation aneurysm model in rabbits.

Radiology 1999;213:223-8.

8. Ding YH, Kadirvel R, Dai D, et al. Creation of bifurcation-type elastase-induced aneurysms in rabbits. AJNR Am J Neuroradiol 2013;34:E19-21.

9. Byrne JV, Beltechi R, Yarnold JA, et al. Early experience in the treatment of intra-cranial aneurysms by endovascular flow diversion: a multicentre prospective study. PLoS One 2010;5:e12492.

10. Ding YH, Danielson MA, Kadirvel R, et al. Modified technique to create morphologically reproducible elastase-induced aneurysms in rabbits. Neuroradiology 2006;48:528-32. 